[WASHINGTON] European and US astronomers are considering merging their plans to build large millimetre-wave astronomy observatories, a move that could result in a single, more sophisticated facility.

But design differences between the US Millimeter Array (MMA) and Europe's proposed Large Southern Array (LSA) still have to be reconciled, and agreement reached on funding for the joint project, which would cost about $\$ 400$ million.

At a meeting last month at the headquarters of the National Radio Astronomy Observatory (NRAO) in Charlottesville, Virginia, both sides agreed that construction and operating costs should be split evenly between Europe and the United States. They also agreed that the array would be located at the 5,000-metre-high Chajnantor site in Chile's Atacama Desert, which had already been chosen for the MMA.

The US plan calls for 40 eight-metre antenna dishes, working together as an interferometer. The European concept is to have fewer dishes but to make them twice as large, so that the LSA's total collecting area would be five times that of the MMA.

The European observatory would not observe at submillimetre wavelengths, but would be better suited to observing very distant, faint objects such as galaxies in the early stages of formation. The MMA in contrast would view larger, more extended sources at higher frequencies.

Scientifically, the two sides should have lit- tle problem agreeing on a common approach, says Robert Brown of the NRAO. But they will need to choose between two design strategies - either keeping the current, different-sized antennas, or coming up with a common, intermediate size.

Each side has something to gain from a merger, say those involved in the discussions. The US National Science Foundation (NSF), which is funding the MMA, has been pressing the NRAO to find an international partner. Talks with Japan, which is also proposing a large millimetre-wave array, have yielded no agreement.

The LSA could benefit from attaching itself to the more mature MMA project, which was included in next year's NSF budget request after more than 15 years of planning. The LSA will not even come up for funding until 2000, says Dennis Downes, an astronomer at the Institut de Radio Astronomie Millimétrique in France, who is participating in the merger discussions.

A joint venture would also bring down the LSA's cost of \$350 million, if Europe had to contribute only $\$ 200$ million as its part of the partnership.

Another advantage of teaming up would be sharing the cost of building roads, buildings and other infrastructure at the site in Chile. That alone could save some $\$ 50$ million, according to Downes. Brown says the NRAO is trying to encourage Japan to build in the same area, if it goes ahead with its array.

US funding for MMA - a proposed $\$ 9$

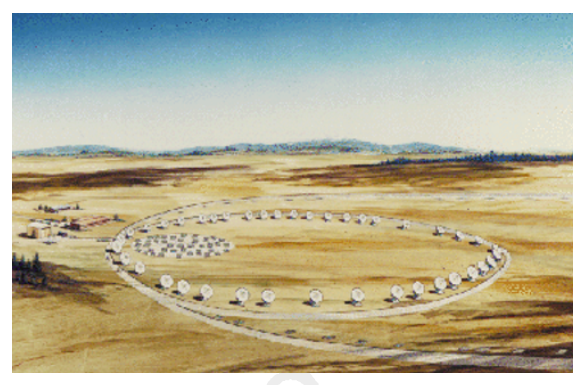

The proposed US Millimeter Array (above) has been under pressure to a seek a partner.

million in 1998 - so far covers only design studies and prototyping. The NRAO plans to build working models of the system's antenna, receiver and other key components by 2000. If these are approved, the full system could be operating by 2006 .

But supporters of the MMA got a rude shock two weeks ago, when the Senate appropriations committee that oversees the NSF's budget raided $\$ 4$ million of the MMA's $\$ 9$ million request to finance the Gemini Telescope, a higher priority, nearer-term project. Brown says the reduction, if it stands, would do "a lot of harm" to a project that already has its hands full developing cutting-edge technology on a short deadline.

He hopes the money will be restored when the House of Representatives and Senate reconcile their two spending bills in the autumn. "To throw out this challenge and then not give us the resources pulls the rug out from under us," he says.

Tony Reichhardt

\title{
Austria to go private in novel solution to grant distribution
}

[MUNICH] A report commissioned by the Austrian government has concluded that all government funding for industrial and academic research should be placed in the hands of a private organization. The new body would also develop long-term research strategies. The government approved the report in principle last month.

The report's authors - Albert

Hochleitner, director general of Siemens Austria, and Arnold Schmidt, president of Fonds zur Förderung der Wissenschaftlichen Forschung (FWF), the funding agency for university research — had been asked to propose how industrial and academic research could be brought closer together. They recommend the establishment of an Office for Research and Technology (BFT), a state-owned private company that would distribute research grants to projects with a defined industrial relevance. The BFT would handle all existing funds, such as the ASch700 million (US\$54 million) of the FWF.

The report also suggests that the BFT would handle the funds of a new foundation,
KIR, which would support the creation of socalled centres of competence, with a budget around twice that of the FWF. Universities and industry would have to apply jointly for support for such new institutes.

The BFT would distribute a total of ASch4-5 billion in grants each year to researchers and universities. It would be scientifically advised and financially controlled by a Council for Research and Technology made up of the ministers for science and for economic affairs, four academics and four industrialists.

The report foresees that direct funding for Austria's universities, where 95 per cent of the country's research is carried out, would be gradually reduced over the next decade, and university scientists would instead compete for funds distributed by the BFT.

Despite the general approval of the plan by the Austrian government, the details of the proposal are likely to be changed by the time a formal cabinet decision is required in September. An official from the research ministry says that there are serious doubts about whether entrusting a private company with political decisions of public interest would accord with Austria's constitution.

The research minister, Casper Einem, suggests that the BFT should be created as an endowment financed jointly by the research budgets of the ministries for research and economy, and proceeds from the privatization of state-owned industries. "The experts were free to think, but now it is up to us to reduce the concept to what is feasible," he says.

Some university staff strongly oppose reducing the research minister's influence on long-term science and technology strategies. They fear that grants may come to depend on the vote of a small but powerful panel of experts driven by economic interests.

"We do not support the concept of transferring responsibility for science policy [from the state] to bolster the power of a group of a few so-called experts," says Margit Sturm, secretary general of the Conference of Scientific University Staff. Quirin Schiermeier 